\title{
The Determinant of Bilateral Trade in the East African Community: Application of the Gravity Model
}

\author{
Ambetsa, Wycliffe Oparanya ${ }^{1}$, Kenneth P. Mdadila ${ }^{2}$ \& Longinus K. Rutasitara ${ }^{3}$ \\ ${ }^{1}$ Department of Economics, University of Dar-es-Salaam, Tanzania \\ Correspondence: Ambetsa, Wycliffe Oparanya, Department of Economics, University of Dar-es-Salaam, P.O. \\ Box 70254 -00400, Nairobi, Kenya. Tel: 254-722-521-856. E-mail: woparanyah@gmail.com
}

Received: January 20, 2019

Accepted: February 10, 2019

Online Published: March 5, 2019

doi:10.5539/ijef.v11n4p1

URL: https://doi.org/10.5539/ijef.v11n4p1

\begin{abstract}
This study examines the determinants of bilateral trade flows within the East African region using the Gravity model approach. Using a 40 year data obtained from the World Development Institute's data base, the Random Effects model is applied to empirically determine the variables that drive bilateral trade within the region.

The findings suggest that country size, contiguity, diaspora remittances and corruption index have a positive impact on the regions bilateral trade. On the other hand, foreign direct investment flows, net population effects and mobile subscription ratio have a negative impact on intra-trade flows among member states. Although not exhaustive, the study offers useful insights for policy makers to seek measures to spur the EAC intra-trade flows.
\end{abstract}

Keywords: determinants, bilateral trade, gravity model, Intra -trade flows

\section{Introduction}

\subsection{Background}

Since independence, the East African Community (EAC) countries, initially comprising of Kenya, Tanzania and Uganda (1967-1977, 1999-2007) and later increased to include Burundi and Rwanda in 2007, and South Sudan in 2016, have recognized the role of trade in their bid to foster rapid and sustained economic growth. Over the years, each country has embraced regional trade policies that encourage trade in order to create employment, investment and transfer productive capacity in their respective domestic economies.

This strong recognition of trade as a key driver of economic growth is manufest through the economic policies adopted shortly after independence and throughout the years to-date. Notably, early trade policies in the region leaned on mercantilist theory of trade (owing to their colonial history) that promoted an export oriented strategy of economic growth. Later on, the regions economies shifted into an import substitution and industrialization era (1960-1980), liberalization (1980-2000) and finally, regionalization and globalization (2000 to present).

\subsection{Role of Trade in EAC Economic Development}

Right from its inception, trade was meant to improve the economic welfare of the East African people through contribution to gross domestic product (GDP) of the trading partners and development of infrastructure, mainly road networks, railway lines, sea routes and air travel. Most importantly, it was meant to act as an integrative tool to harmonize the EAC economies into a cohesive economic development partners.

This could be realized through the generation of scarce foreign exchange reserves, attraction and share of new technologies and growth of related and associated industries. Trade exports can also cution domestic ecenomies against external economic shocks (Senhadji \& Montenegro, 1999). Other welfare effects from trade include maintenance of harmonious and peaceful relations among trading partners, exchange of cultural values and beneficial virtues and development of communication channels and common languages.

\subsection{Statement of the Problem}

Several studies have been done to determine both inter and intra-country trade in East Africa. Ochieng' and Maxon (1992) posit that Kenya's percentage contribution to the total value of the EAC inter-territorial trade increased from 36.2 percent in 1945 to 65.7 percent in 1966, compared to a decrease from 41.0 percent to 23.7 percent and 22.8 percent to 10.6 percent for Uganda and Tanzania respectively. However, Ammon, Mjema, and Kilindo (2002) demostrates a reversal of this trade since 1997, with Tanzania's imports to exports ratio declining 
from 11.5 in 1996 to 2.52 in 2001.

Intra-African trade is still very low compared to intra-regional trade in other parts of the world. For the period 2004-2006, intra-African exports represents 8.7 per cent of total Africa's exports, while intra-African imports represents 9.6 per cent of total imports. This in comparative to 20.9 and 18.5 per cent for Developing America, 48.1 and 45.5 per cent for Developing Asia, and 68.1 and 71.4 per cent, respectively for Developed Europe. For the period 1960-2006, Africa has had on average a low proportion of intra-regional trade compared to other regions of the world (Economic Development Report in Africa, 2009).

Subramanian and Tamirisa (2001) indicate that the prime determinants of trade in Africa in general terms are income, geography and size. Similar views are shared by Foroutan and Pritchett (1993), Coe and Hoffmaister (1999) and Rodrik (1999). But the exact manner in which these factors, inter alia, drive bi-lateral trade in the EAC region are less clear.

\subsection{The Objectives of the Study}

The objectives are:

1) To determine the patterns and trends of bilateral trade in the EAC region.

2) To identify the problems that hinder bilateral trade in the EAC region.

3) Make policy recommendations on how to promote both inter and intra trade growth rates in the EAC region.

The study contributes to the body of knowledge by adducing new insights into the determinants of bilateral trade within the EAC region. Second, it delineates knowledge gaps on bilateral trade in the EAC and proffers conclusive and persuasive empirical evidence on the same. Third, the study utilizes empirical estimation procedures that integrates spatial and temporal approaches for the first time in the EAC region. Finally, it utilizes the longest data set thus far, spanning a 40 year period between 1970-2010.

The rest of the study is organized into four sections. Section two reviews the relevant literature and demonstrates the knowledge gap it seeks to address; Section three discusses the study methodology; Section four presents and discusses the study findings; while section five presents the conclusions.

\section{Relevant Literature}

\subsection{Brief History of Trade in the EAC Region}

Trade among the six EAC member states has fluctuated across time and space due to geopolitical and economic changes. Figure 1 tracks intra-trade flows in the region based on the World Bank data. Obviously, the figure demonstrates low levels of trade among EAC countries except for Kenya from 1990-2006.

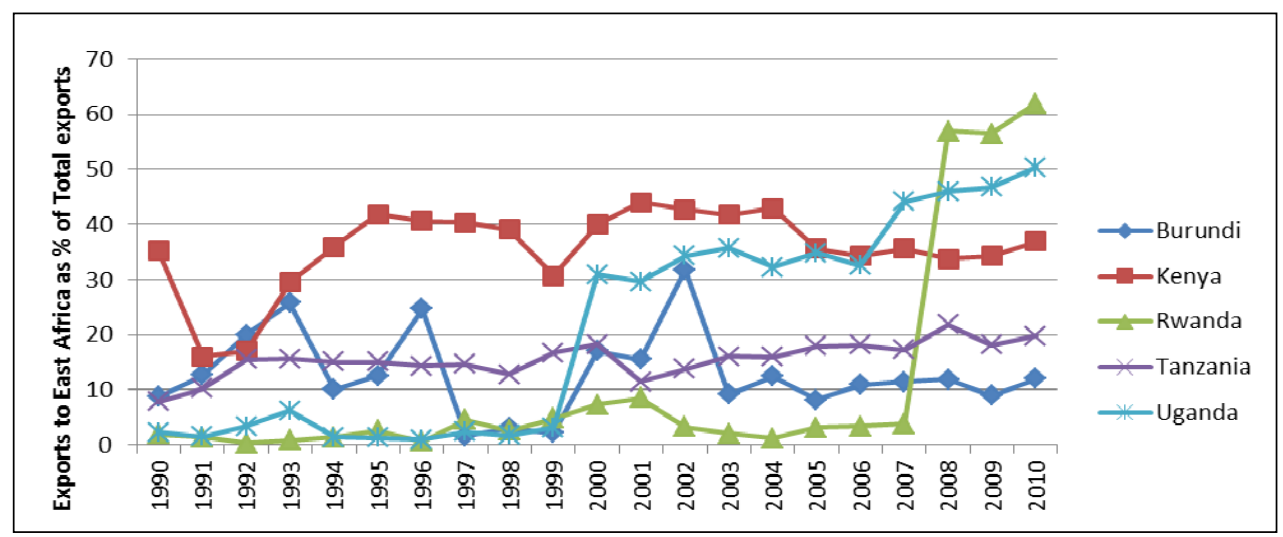

Figure 1. Merchandise exports to within East Africa region as a \% of Total Exports (1990-2010)

Source: World Bank Data, World Development Indicators.

The regions' economy weathered the global economic crisis to register a positive real growth rate of 5.8 percent in 2009. Kenya remains the regional trade hub (Figure 2) and the transport link to the world for many of the EAC countries. 


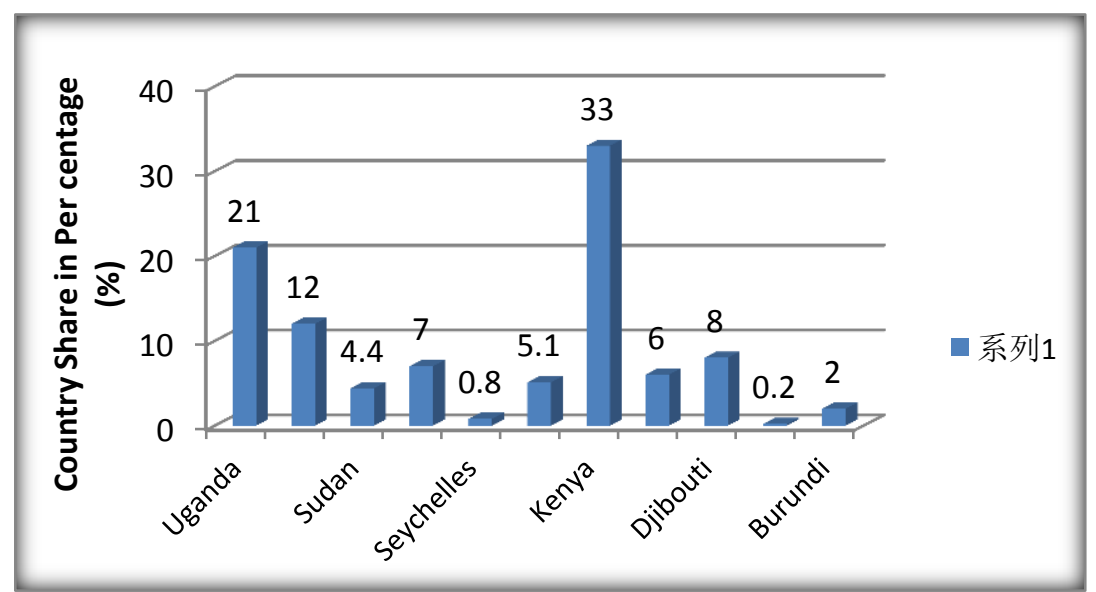

Figure 2. Percentage share of East African intra-regional trade by country Source: IMF as reported in AfDB and ADF report, 2010.

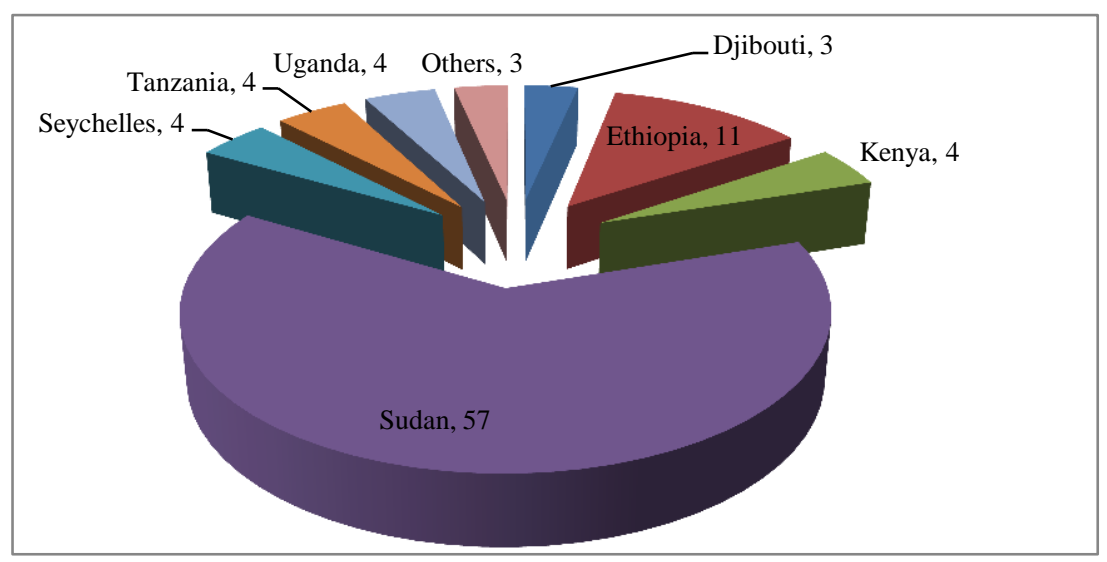

Figure 3. Foreign direct investment flows to East Africa by countries: annual averages (\%) 2000-2008 Source: AfDB and ADF Report, 2010.

FDI flows into the region are very low probably due to instability and governance challenges. FDI flows to the individual countries in the region (figure 3), indicates that Sudan attracted the highest share (57 percent) mainly due to foreign investments in the oil sector, followed by Uganda (14 percent) and Ethiopia (11 percent). The shares of the other countries were limited to 4 percent or below.

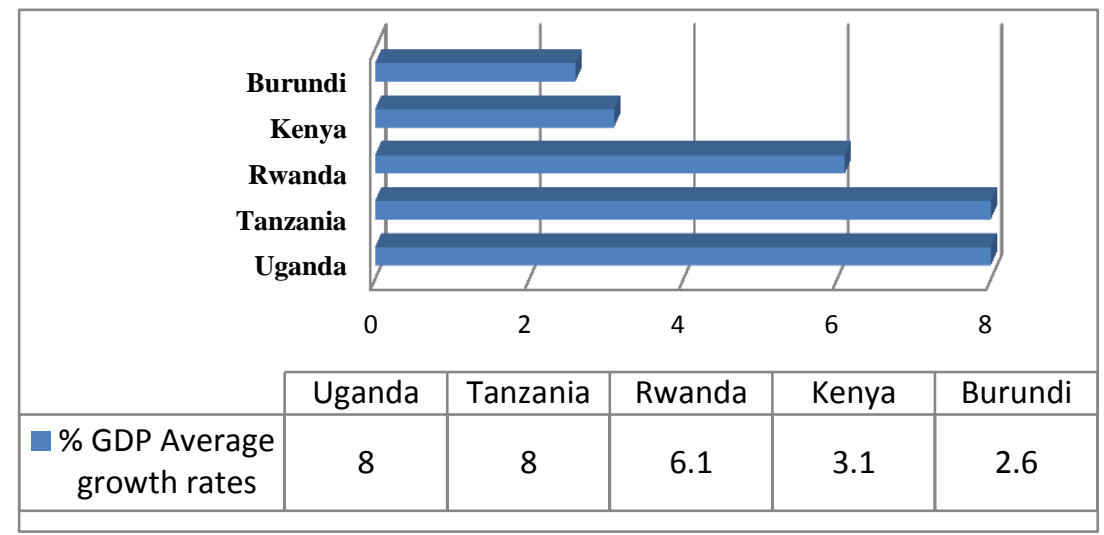

Figure 4. Average real GDP growth rates per EAC country 2000-2009 (\%) 
Figure 4, demostrates disparities in GDP, economic growth and economic structures as a likely obstacle to integration in the EAC. Since independence, EAC has highly dependent on agriculture, nearly accounting for three fifths of its total product, particularly coffee, cotton, sisal and recently horticultural products and tropical fruits. Despite improvements in agricultural productivity, per capita income remains low.

\subsection{Empirical Application of Gravity Models}

The Gravity model has widely been used to empirically investigate patterns of bilateral trade. It is premised on the "Law of Universal Gravitation" advanced by Isaac Newton in 1687. He argued that the attractive force F between two objects $i$ and $j$ is given by:

$$
F_{i j}=G \frac{M_{i} M_{j}}{D_{i j}^{2}}
$$

Where:

$\mathrm{F}$ is the "attractive force," $\mathrm{M}$ are the masses, $\mathrm{D}$ the distance between the objects, and $\mathrm{G}$ the gravitational constant defined by the units of measurement for mass and force. Jan Tinbergen (1962) proposed a similar form to explain trade flows:

$$
F_{i j}=G \frac{M_{i}^{\alpha} M_{j}^{\beta}}{D_{i j}^{\theta}}
$$

Where:

$F_{i j}$ is the trade flows from i to $\mathrm{j} ; M_{i}$ and $M_{j}$ are "economic masses" (Size); $D_{i j}$ is the distance between the two locations; and $\mathrm{G}$ is a constant (equal to Newton's law if $\alpha=\beta=1$ and $\theta=2$ ).

Taking the logs of this equation gives the following estimable but linearized equation:

$$
\operatorname{In} F_{i j}=\alpha \operatorname{In} M_{i}+\beta \operatorname{In} M_{j}-\theta \operatorname{In} D_{i j}+\operatorname{In} G+\varepsilon_{i t}
$$

Given $\varepsilon$ is a classical error term, then the equation can be estimated using ordinary least squares (OLS).

The logic of gravity models is that the larger an economy is, the larger it is likely to spend on imports due to its high average income levels. Conversely, due to its' high productive capacity, a large economy is likely to attract a large share of spending from other countries because it's bound to have a wide variety of manufactured products. Thus, trade between any two countries is larger, the bigger either economy is. If trade volumes between any two countries differ from the predictions of Gravity models, the economists find an explanation for such anomalies.

For instance, Krugman and Obstfeld (2006) find trade between three European countries (Ireland, Netherlands and Belgium) and the United States (US) to be higher than what is predicted by gravity models. They argue that the economic reason for such a trade anomaly would be cultural affinity for trade flows between Ireland and the US since millions of Americans are of Irish descent. In the case of Netherlands and Belgium, the reason could be due to geography and transport since both countries are located near the mouth of Rhine, Western Europe's longest river that runs past the Germany's industrial heartland.

Deardorff (2001) argues for unobservable trading costs rather than factor endowments and technology as important explanatory variables for international trdae flows while Anderson (2001) posits that informal trade barriers could explain the existence of large trade volumes for similar countries like is the case between the US and Canada. McCallum (1995) confirms the esistence of informal trade barriers as good expanatory factors for home bias or border effect in trade. Obstfeld and Rogoff (2000) argues for the case of unobserved trade costs in explaining some of the puzzles in international economics.

Anderson and Van Wincoop (2000) demonstrates that gravity models can be used to compute the impact of borders on both intra-national trade (within a country) and international trade. Serlanga and Shin (2007) argues that gravity models have widely been applied to explain the movement of goods and services across national and regional bounderies since the early 1940s. Futher, the gravity model is a good fit for trade policy analysis, explanation of currency unions and varied trade distortions (Bougheas, Demetriades, \& Morgenroth, 1999; De Grauwe \& Skudelny, 2000; Glink \& Rose, 2002; De Sousa \& Disdier, 2002).

However, despite the wide empirical application of the gravity model, it has historically been criticised as to lack a strong theoretical underpinnings (Serlanga \& Shin, 2007). But Anderson (1979) explain that the Ricardian models, Heckscher-Olin (H-O) models and increasing returns to scale (IRS) models of the New Trade Theory provide a good theoritical foundation for the gravity model.

Okubo (2006) successfully applied the economic gravity model analysis to examine the border effects on Intra - 
Empire versus Extra -Empire trade for the Japanese Empire that includes Mainland Japan, Korea and Formosa (Taiwan) with her 24 non- Empire countries namely; India, the Netherlands, Indies, China, Russia, the United Kingdom, Canada, Australia, New Zealand, Norway, Denmark, Sweden, Switzerland, Italy, German, France, Belgium, Spain, Argentina, Brazil, Mexico, the United States, Chile and Peru based on data for 1915, 1920, 1925, 1930, 1935 and1938.

Serlanga and Shin (2007) applied the gravity model to analyze bilateral trade flows among the fifteen European countries. They find that the impact of the GDP variables, similar relative size of trading partners, differences in relative factor endowments and common border to be significant and positive. The impact of distance and foreign population are found to be significantly negative. Egger and Pfaffermayr (2002) analyzes the impact of distance on bilateral exports and outward FDI and finds distance to non-trivialy affect both exports and outward FDI.

Longo and Sekkat (2001) applies the gravity model to examine obstacles to intra-African trade (IAT). In addition to the traditional gravity models variables (income, income per capita, GDP, distance and surface area), they include trade policy; inadequate infrastructure; currency inconvertibility; diversity in ethnicity, culture and language; and political instability. They confirm that the economic size of a country, incomes and level of development impacts trade flows. As expected, distances and country dimension are found to negatively affect trade flows. Infrastructure, sound economic policies and political instability are found to have a significant efects on trade flows.

Villoria (2008) uses gravity modelling to explore the amount of missing intra-African trade for manufacturers. He estimates that of the 54 member states bilateral trade transactions, about 41 percent were missing. Besides, it is predicted that the regions manufacturing exports are worth about 300 million USD, but only 2.5 percent is formally documented.

Eita and Ashipala (2008) used the Gravity model to examine the determinants of export flows in Namibia. They find increases in importerting country's GDP and domestic GDP to have positive effects on Namibian exports. On the other hand, the Importing country's GDP per capita had a negative effect on exports, while domestic GDP per capita and real exchange rates were insignificant. As expected, distance was associated with a decrease in exports. Overall, membership in SADC, EU and border sharing had positve impacts on exports.

\subsection{Gravity Models and Intra-African Trade}

Empircal evidence on intra-African trade suggests that flows could be enhanced if obstacles that impede it are removed. The main obstacle is high trading costs arising from transport, border and behind border costs. Econometric estimates suggest transport costs in Africa are 136 per cent more than in other parts of the world largely due to poor infrastructure (Amjadi \& Yeats, 1995; Limao \& Venables, 2001).

Limao and Venables (2001) estimate that if the median for tranpsot costs was doubled, trade volumes could be reduced by 45 per cent. For land locked countriessuch costs would be 50 per cent more and trade volumes 60 per cent less. Border costs include breakdowns of the electronic systems, poor coordination during inspections, inadequate working hours at ports of entry and delays in processing refunds for customs duty. These cumulatively increase cost of intra-African trade (Gad, 2009). Coulibaly and Fountagn'e (2005) estimates that it costs about 4 percent more to cross a transit territory irregardless of the distance covered.

Other constraints that impact trade negatively include corruption and lack of predictability (Longo \& Sekkat 2004); missing or poor quality physical infrastructure (Gad, 2009; Limao \& Venables, 2001; Ndulu, 2006); lack of efficient and reliable telecommunications, financial intermediation and logistics (Njinkeu, Wilson, \& Fosso, 2008; Foster, 2008); and soft infrastructure like policy, regulatory environment and business administration. Improvements of this soft infrastructure are important for the realization of the benefits of better hard infrastructure (Portugal-Perez \& Wilson, 2008).

\subsection{Modification of the Theoretical Gravity Model for Empirical Estimation of EAC Trade}

Often the Gravity Model has been criticized on the grounds of mis-specification and inability to deal with heterogeneity. Thus, a panel or longitudinal based approach is desirable since heterogeneity problems can be addressed by the inclusion of country-pair "individual" effects. Matyas (1997) however advocates for a "triple-way model", as the correct econometric specification in which time, exporter and importer effects are defined as fixed and unobservable. But, Egger and Pfaffermayr (2002) demostrates that the extension of Matays' triple-way model to include bilateral trade interaction effects reduces it to a two-way conventional model with time and bilateral effects only.

Serlanga and Shin (2007) observe that even though the pooled OLS, the Fixed and Random Effects Models have 
been widely used in varied situations,most studies reject the assumption of unobserved individual effects to be uncorrelated with all the regressors. Therefore, the Fixed Effects (FE) estimation is considered as more acceptable (Cheng \& Wall, 2002). However, it fails to take into account time invariant variables like distance, border effects or common language dummies which are important in the EAC region.

Cheng and Wall (2002) opine that we could ignore potential correlation between individual specific variables and (unobserved) individual effects and simply estimate individual effects of specific variables by OLS. But doing so would result in biased estimates. Thus, a plausible proposition to resolve the problem is to use the Hausman and Taylor (1981, hereafter referred to as HT) instrumental variable estimation technique as exemplified by Brun, Carrere, Guillaumont, and De Melo (2002).

\subsection{Model Specification and Control for Biased Estimates}

Serlanga and Shin (2007) outlines the following typical gravity equation of international trade:

$$
y_{h f t}=\alpha_{0}+\theta_{t}+\beta_{1 t} X_{h f t}+\beta_{2 t} X_{h t}+\beta_{3 t} X_{f t}+\beta_{4 t} Z_{h f}+\mu_{h f t}
$$

for $h=1, \ldots, N, f=1, \ldots, N, h \neq f, t=1, \ldots, T$,

where $y_{h f t}$ is the dependent variable (say, the volume of trade from home country h to target country $\mathrm{f}$ at time $\mathrm{t}$ ), $X_{h f t}$ are explanatory variables with variation in all the three dimensions (say, exchange rates between local currencies), $X_{h t}, X_{f t}$ are explanatory variables with variation in $\mathrm{h}$ or $\mathrm{f}$ and $\mathrm{t}$ (say, GDP or population), $Z_{h f}$ are explanatory variables that do not vary over time but vary in $\mathrm{h}$ and $\mathrm{f}$ (say, distance between the capital cities of the respective east African member countries), and the disturbance terms $\mu_{h f t}$ are assumed to be iid with zero mean and constant variance across all $h, f, t$.

Equation (4) is estimated by the cross-section OLS for each year, where $\alpha_{0}$ and $\theta_{t}$ cannot be separately identified. However, this cross-section OLS ignores any heterogeneous characteristics related to bilateral trade relationship. For instance, Kenya could export different amounts of the same product to Rwanda and Tanzania even if their GDPs are identical and they are equidistant from Kenya. Thus, the cross-section OLS estimates are likely to suffer from substantial heterogeneity bias.

To address heterogeneity, we include country-pair "individual" effects. Imposing $\beta_{j t}=\beta$ for all $\mathrm{t}$ and $\mathrm{j}=1, \ldots . .4$, and $\theta_{t}=0$ in (4), we obtain the following pooled panel data model:

$$
y_{h f t}=\alpha_{0}+\beta_{1} X_{h f t}+\beta_{2} X_{h t}+\beta_{3} X_{f t}+\beta_{4} Z_{h f}+\mu_{h f t}
$$

Matyas (1997) observed that the gravity model based on the pooled specification (5) may essentially be mis-specified, and hence proposed that the proper econometric specification of the gravity model should be a three-way model:

$$
y_{h f t}=\alpha_{0}+\alpha_{h}+\gamma_{f}+\theta_{t}+\beta_{1} X_{h f t}+\beta_{2} X_{h t}+\beta_{3} X_{f t}+\beta_{4} Z_{h f}+\mu_{h f t}
$$

where one dimension is time-specific effect $\left(\theta_{t}\right)$, and the other two are time invariant export and import country-specific effects $\left(\alpha_{h}\right.$ and $\left.\gamma_{f}\right)$.

For the EAC region, these unduly strict restrictions could be specified as $\alpha_{h}=\gamma_{f}=\theta_{t}=0$ for all $\mathrm{h}, \mathrm{f}$, and $\mathrm{t}$ are imposed in (5). Whilst estimating both models (5) and (6), Matyas found a statistically significant evidence against restrictions, $\alpha_{h}=\gamma_{f}=\theta_{t}=0$. Similarly, Egger and Pfaffermayr (2002) showed that when the Matyas model (6) is expanded to include bilateral trade interaction effects such as those observed in the EAC region, it can be extended to reflect the following equation:

$$
y_{h f t}=\alpha_{0}+\alpha_{h}+\gamma_{f}+\theta_{t}+\alpha_{h f}+\beta_{1} X_{h f t}+\beta_{2} X_{h t}+\beta_{3} X_{f t}+\beta_{4} Z_{h f}+\mu_{h f t}
$$

then, as pointed out by Serlanga and Shin (2007), this generalized three way specification is identical to a two way model with time and bilateral effects only. Thus, Matyas' model (6) is still likely to be mis-specified as it fails to display the whole vector space of possible treatments of explaining variations in bilateral trade.

Cheng and Wall (2002) focuses on the issue of heterogeneity bias and proposed the following fixed effects model (FEM):

$$
y_{h f t}=\alpha_{0}+\alpha_{h f}+\theta_{t}+\beta_{1} X_{h f t}+\beta_{2} X_{h t}+\beta_{3} X_{f t}+\beta_{4} Z_{h f}+\mu_{h f t}
$$

The main characteristic that sets it apart from Matyas' model specified above is the inclusion of country-pair effects that are allowed to differ accordingly with the direction of trade, i.e. $\alpha_{h f} \neq \alpha_{f h}$.

Thus, (6) could be viewed to be a special case of (8), where the ad hoc cross-country restrictions on the country-pair effect are imposed, i.e. $\alpha_{h f}=\alpha_{h}+\gamma_{f}$. Cheng \& Wall (2002) also consider the Symmetric Fixed Effect (SFE) and the Difference Fixed Effect model (DFE) models. The former imposes a restriction of 
symmetric country-pair effects, i.e. $\alpha_{h f}=\alpha_{f h}$, whilst the latter uses first differencing to (8) in order to eliminate the fixed effects. Available empirical evidence suggests that the restrictions imposed in (5), symmetry restriction on country-pair effects and those needed to obtain DFE specification are all rejected. Thus, Cheng and Wall (2002) conclude that the FEM (8) is likely to be the most robust version of gravity model applicable in studies of international trade flows.

However, thre still exist a challenge to establish the right measure of economic distance and control for contiguity (e.g., considering Kenya and Tanzania, Rwanda and Uganda, Ethiopia and South Sudan are all equivalently contiguous pairs). Thus, it would be necessary to regress the (estimated) individual effects on individual-specific variables by the OLS (Cheng \& Wall, 2002; Martinez-Zaroso \& Nowak-Lehmann, 2003).

But still, this approach may still be dogged by rpoblems of likely correlation between individual specific variables and (unobserved) individual effects. To include time-varying, time-invariant and unobserved individual effects, the HT instrumental technique is used.

However, the triple index model (8) may not the only way to represent panel data for EAC Gravity Model. A conventional double index-based panel data could still be used combine the characteristics of trading partners as explanatory variables e.g. Egger (2001) and Glink and Rose (2002). Thus, Serlanga \& Shin (2007) consider the following double index panel data model:

$$
y_{i t}=\beta X_{i t}+\gamma Z_{i}+\alpha_{i}+\theta_{t}+\varepsilon_{i t}, \mathrm{i}=1, \ldots, \mathrm{N}, \mathrm{T}=1, \ldots, \mathrm{N}
$$

where an index i represents each country-pair $h f$ such that $\alpha_{i}=\alpha_{h f}=\alpha_{h}+\gamma_{f}$ as in Cheng and Wall (2002). Notice that variables in $X_{i t}$ are defined as a combination of features of the countries in each pair, but importantly embrace variables, $X_{h f t}$ that vary in all the three dimensions, and variables, $X_{h t}$ and $X_{f t}$ that vary only with one partner of trade and time, respectively. Time invariant regressors such as distance, common language and common borders dummies are now included in $Z_{i}$ that coincide with $Z_{h f}$.

De Sousa and Disdier (2002) use (9) explores the role of consumer's preferences, tariff and non-tariff barriers in explaining border effects on trade flows among Hungary, Romania, Slovenia, European Union (EU) and Central European Free Trade Agreement (CEFTA) countries. They use the HT estimation to examine the effects of individual country's characteristics such as distance, common border or language.

From the foregoing, we may conclude that the FEM together with the HT is the best suitable techniques to analyse EAC trade flows.

\subsection{The Haussmann-Taylor Estimation in Heterogeneous Panels with Time-specific Factors in EAC Region}

Since both triple and double index versions of the gravity model of trade, (8) and (9), can be expressed as a conventional double index panel-data model, we begin with

$$
y_{i t}=\beta X_{i t}+\gamma Z_{i}+\varepsilon_{i t}, \mathrm{i}=1, \ldots \ldots, \mathrm{N}, \mathrm{t}=1, \ldots, \mathrm{T}
$$

And noting that,

$$
\varepsilon_{i t}=\alpha_{i}+\theta_{t}+\mu_{i t}
$$

where the error term $\varepsilon_{i t}$ is composed of three parts; namely, $\alpha_{i}$ is an individual effect that accounts for the effect of all possible time invariant determinants and could be correlated with some of the explanatory variables $X_{i t}$ and $Z_{i}, \theta_{t}$ is the time-specific effects common to all cross section units that is meant to correct for the impact of all the individual invariant determinants such as potential trend or business cycle, and $\mu_{i t}$ is a zero mean idiosyncratic random disturbance uncorrelated across cross section units and over time periods. The conventional assumptions are that these three components are independent of each other in the EAC setting.

It is now possible to generalize (11) such that the individual responses to variations of the common time-specific effects are heterogeneous. Thus (11) can be extended to

$$
\varepsilon_{i t}=\alpha_{i}+\lambda_{i} f_{t}+\mu_{i t}
$$

Where $\lambda_{i}$ capture heterogeneous responses that trade flows between trading countries might have with respect to the time-specific common factors, $f_{t}$. Therefore, the pooled or FE estimation of $\beta$ and $\gamma$ in (10) may be less efficient without properly accommodating the error component structure given by (12). Most importantly, where some or all of the regressors in $X_{i t}$ are likely to be correlated with $f_{t}$, the uncorrected estimator could be severely biased. Recently, a number of panel studies have used (12) explicitly, i.e., Ahn, Lee, and Schmidt (2001), Bai and Ng (2002), Pesaran (2002) and Phillips and Sul (2002).

To account for this potentially important issue, it is prudent to combine (10) and (12). Here, two cases are 
considered as a way of taking account of the unique settings observed in the EAC region. First, we simply assume that all of the time-specific common effects are observable in which case we have:

$$
\begin{gathered}
y_{i t}=\beta X_{i t}+\gamma Z_{i}+\lambda_{i} f_{t}^{*}+\varepsilon_{i t}, \mathrm{i}=1, \ldots, \mathrm{N}, \mathrm{t}=1, \ldots \mathrm{T} \\
\varepsilon_{i t}=\alpha_{i}+\mu_{i t}
\end{gathered}
$$

Where $f_{t}^{*}$ are observed multiple time-specific factors. The unique and probably most revealing features of the above model are: (i) it considers explicitly the impacts of time-specific factors $f_{t}^{*}$ instead of the conventional fixed time effects to investigate the business cycle or the globalization issues; and (ii) it does not impose the homogeneous restriction on the coefficients on $f_{t}^{*}$.

Considering that $f_{t}^{*}$ usually measure the common macro shocks or policies likely to be rampant in EAC, it is natural to expect that bilateral trade responses will be different from each other in the region. Secondly, in the case of both observed and unobserved common time-specific effects, it is wise to pursue a Pooled Correlated Common Effect (PCCE) estimation approach advanced by Pesaran (2002), and hence extend the model (13) to:

$$
y_{i t}=\beta X_{i t}+\gamma Z_{i}+\lambda_{i} f_{t}+\alpha_{i}+\mu_{i t}, \mathrm{i}=1, \ldots, \mathrm{N}, \mathrm{t}=1, \ldots, \mathrm{T}
$$

where we assume that there is a single unobserved time-specific common effect in $\varepsilon_{i t}$ and then $f_{t}$ is the augmented set including $f_{t}^{*}$ and the cross sectional averages of $y_{i t}$ and $X_{i t}$, that is, $\overline{y_{t}}=N^{-} \sum_{i=1}^{N} y_{i t}$ and $\overline{X_{t}}=N^{-1} \sum_{i=1}^{N} X_{i t}$.

Pesaran (2002) shows that the PCCE estimation (also called the generalised within estimator) will provide the consistent estimator of $\beta$, though it does not provide a consistent estimator of $\gamma$. Serlenga and Shin (2007) work on (15) without loss of generality. They begin by recognizing that the notations; $X_{i t}=\left(x 1_{i t}, x 2_{i t}, \ldots, x k_{i t}\right)$ is a k x 1 vector of variables that vary over individuals and time periods. They also note that $Z_{i}=\left(z 1_{i}, z 2_{i}, \ldots, z g_{i}\right)$ is a $\mathrm{g}$ $\mathrm{x} 1$ vector of individual-specific variables, $f_{t}=\left(f 1_{t}, f 2_{t}, \ldots, f l_{t}\right)$ is an $1 \mathrm{x} 1$ vector of time-specific variables, and $\beta=\left(\beta_{1}, \beta_{2}, \ldots, \beta_{k}\right), \quad \gamma=\left(\gamma_{1}, \gamma_{2}, \ldots, \gamma_{g}\right), \lambda=\left(\lambda 1_{i}, \lambda 2_{i}, \ldots, \lambda l_{i}\right)$ are conformably defined column vectors of parameters, respectively. They follow HT and rewrite (15) as:

$$
y_{i t}=\beta_{1} x_{1 i t}+\beta_{2} x_{2 i t}+\gamma_{1} z_{1 i}+\gamma_{2} z_{2 i}+\lambda_{i} f_{t}+\alpha_{i}+\mu_{i t}
$$

where $X_{i t}=\left(x 1_{i t}, x_{2 i t}\right), Z_{i}=\left(z 1_{i}, z_{2 i}\right), x 1_{i t}, x_{2 i t}$ are $k_{1}$ - and $k_{2}$-vectors, $z 1_{i}, z_{2 i}$ are $g_{1}$ - and $g_{2}$-vectors, and $\beta_{1}, \beta_{2}, \gamma_{1}, \gamma_{2}$ are conformably defined column vectors. The following assumptions are then made:
a) $\quad \mu_{i t} \sim \operatorname{iid}\left(0, \sigma_{\mu}^{2}\right)$
b) $\quad \alpha_{i} \sim$ iid $\left(\alpha, \sigma_{\alpha}^{2}\right)$
c) $E\left(\alpha_{i} \mu_{j t}\right)=0$ for all $\mathrm{i}, \mathrm{j}, \mathrm{t}$.
d) $E\left(X_{i t} \mu_{j s}\right)=0, E\left(f_{t} \mu_{i s}\right)=0$, and $E\left(Z_{i} \mu_{j t}\right)=0$ for all $\mathrm{i}, \mathrm{j}, \mathrm{s}, \mathrm{t}$, so all the regressors are exogenous with respect to the idiosyncratic errors, $\mu_{i t}$.
e) $x 1_{i t}, z 1_{i}$ and $f_{t}$ are uncorrelated with $\alpha_{i}$ for all $\mathrm{i}$, t, whereas $x_{2 i t}$ and $z_{2 i}$ are correlated with $\alpha_{i}$.
f) Both $\mathrm{N}$ and $\mathrm{T}$ are sufficiently large.

In particular, we need to use prior information to distinguish columns of $\mathrm{x}$ and $\mathrm{z}$ which are correlated with the individual unobservable effect, $\alpha_{i}$ and those which are not. Assumption (d) is necessary to consistently estimate (nuisance) heterogeneous parameters, $\lambda_{i}$.

Serlenga and Shin (2007), develop the estimation theory for all the parameters in (16), using a two step approach that involves two steps i.e. they first, rewrite (13) as

$$
y_{i t}=\alpha_{i}+\beta X_{i t}+\gamma Z_{i}+\lambda_{i} f_{t}+\mu_{i t}, \mathrm{i}=1, \ldots, \mathrm{N}, \mathrm{t}=1, \ldots, \mathrm{T}
$$

and then obtain the consistent estimator of $\beta$ thereafter.

\section{Methodology}

\subsection{Data Collection and Description}

Data for this study was obtained from the World Development Institute (WDI). Table 1 presents the definition of terms used to model in the study while Table 2 presents the summary statistics of the data. The panel data was analysed using the simple OLS regression and Random Effects methods. Instrumental and dummy variables were introduced to solve the problem of unobserved data with all efforts necessary undertaken to avoid the dummy variable trap. 
Table 1. Definition of variables used in modeling

\begin{tabular}{cl}
\hline Variable & Definition/description of variable \\
\hline $\mathbf{E}$ & Export values in millions of US dollars (US\$) that signify trade flows across borders \\
$\mathbf{G D P}_{\mathbf{i}}$ & Gross Domestic Product of exporting country in billions of US dollars (US\$) \\
$\mathbf{G D P}_{\mathbf{j}}$ & Gross Domestic Product of importing country in billions of US dollars (US\$) \\
$\mathbf{G D P}_{\mathbf{i}}$ & GDP per capita of exporting country in US dollars (US\$) \\
$\mathbf{G D P c}_{\mathbf{j}}$ & GDP per capita of importing country in US dollars (US\$) \\
$\mathbf{S c}$ & Trading partners that shared the same colonial master dummy \\
$\mathbf{B s}$ & Trading partners that share a border dummy \\
$\mathbf{D}$ & The distance between the capital cities of the trading partners in Kilometres \\
$\mathbf{A d}$ & The physical distance between the main trading centres of trading partners \\
$\mathbf{G d}$ & The gravity distance and/or contiguity that proxy trading costs associated with distances between the main trading centres \\
$\mathbf{C l}_{\mathbf{i}}$ & of trading partners \\
$\mathbf{C l}_{\mathbf{j}}$ & Existence of a coast line for the exporting county dummy \\
$\mathbf{F D I}_{\mathbf{i}}$ & The annual average foreign direct investment flows in billions of US dollars (US\$) of exporting country \\
$\mathbf{F D I}_{\mathbf{j}}$ & The annual average foreign direct investment flows in billions of US dollars (US\$) of importing country \\
$\mathbf{P}_{\mathbf{i}}$ & The population of exporting country in millions \\
$\mathbf{P}_{\mathbf{j}}$ & The population of Importing country in millions \\
$\mathbf{R c}_{\mathbf{i}}$ & Exporting country membership into a regional trading block dummy \\
$\mathbf{R c}_{\mathbf{j}}$ & Importing country membership into a regional trading block dummy \\
$\mathbf{M p}_{\mathbf{i}}$ & Number of mobile phone subscriptions of exporting country in millions \\
$\mathbf{M p}_{\mathbf{j}}$ & Number of mobile phone subscriptions of importing country in millions \\
$\mathbf{W}_{\mathbf{i}}$ & Value of diaspora remittances in exporting country in US dollar millions (US\$) \\
$\mathbf{W}_{\mathbf{j}}$ & Value of diaspora remittances in importing country in US dollar millions (US\$) \\
$\mathbf{C I}_{\mathbf{i}}$ & The corruption index of the exporting country \\
$\mathbf{C I}_{\mathbf{j}}$ & The corruption index of the importing country \\
$\mathbf{L c}$ & Sharing a common language between trading partners dummy \\
\hline &
\end{tabular}

Table 2. Data summary and descriptive statistics

\begin{tabular}{lccccc}
\hline & \multicolumn{5}{c}{ Descriptive statistics } \\
\cline { 2 - 6 } Variable & Mean & Std. Dev. & Min & Max & Obs \\
\hline $\mathrm{E}$ & 23.5246 & 70.6192 & 0.0000 & 727.11 & 840 \\
$\mathrm{GDP}_{\mathrm{i}}$ & 5.6581 & 5.4671 & 0.2854 & 31.3600 & 840 \\
$\mathrm{GDP}_{\mathrm{j}}$ & 5.5923 & 5.4185 & 0.2854 & 31.3600 & 840 \\
$\mathrm{GDPc}_{\mathrm{i}}$ & 341.4388 & 257.6441 & 57.642 & 999.000 & 840 \\
$\mathrm{GDPc}_{\mathrm{j}}$ & 324.2341 & 239.3187 & 57.642 & 999.000 & 840 \\
$\mathrm{Sc}$ & 0.4274 & 0.4950 & 0.0000 & 1.0000 & 840 \\
$\mathrm{Bs}$ & 0.8095 & 0.3929 & 0.0000 & 1.0000 & 840 \\
$\mathrm{D}$ & -897.4048 & 356.8202 & -1427.000 & -177.000 & 840 \\
$\mathrm{Ad}$ & 897.4048 & 356.8202 & 177.0000 & 1457.0000 & 840 \\
$\mathrm{Gd}_{\mathrm{Cl}}$ & 0.0016 & 0.0014 & 0.0007 & 0.0057 & 840 \\
$\mathrm{Cl}_{\mathrm{j}}$ & 0.4286 & 0.4952 & 0.0000 & 1.0000 & 840 \\
$\mathrm{FDI}_{\mathrm{i}}$ & 0.3810 & 0.4869 & 0.0000 & 1.0000 & 840 \\
$\mathrm{FDI}_{\mathrm{j}}$ & 7.4600 & 1.6600 & -1.1900 & 9.3600 & 840 \\
$\mathrm{P}_{\mathrm{i}}$ & 7.3900 & 1.6600 & -1.1900 & 9.3600 & 840 \\
$\mathrm{P}_{\mathrm{j}}$ & 16.3765 & 10.5481 & 3.522 & 43.095 & 840 \\
$\mathrm{Rc}_{\mathrm{i}}$ & 15.9798 & 10.2563 & 3.522 & 43.095 & 840 \\
$\mathrm{Rc}_{\mathrm{j}}$ & 0.3226 & 0.4678 & 0.0000 & 1.0000 & 840 \\
$\mathrm{Mp}_{\mathrm{i}}$ & 0.3226 & 0.4678 & 0.0000 & 1.0000 & 840 \\
$\mathrm{Mp}_{\mathrm{j}}$ & 788428.6 & 2810626 & 0.0000 & 1.9400 & 840 \\
$\mathrm{~W}_{\mathrm{i}}$ & 760623.6 & 2732004 & 0.0000 & 1.9400 & 840 \\
$\mathrm{~W}_{\mathrm{j}}$ & 4.9300 & 1.4700 & 999.0000 & 7.7800 & 840 \\
$\mathrm{CI}_{\mathrm{i}}$ & 5.4600 & 1.5400 & 999.0000 & 7.7800 & 840 \\
$\mathrm{CI}_{\mathrm{j}}$ & 2.4033 & 0.3807 & 1.8000 & 3.3000 & 183 \\
$\mathrm{Lc}$ & 2.3985 & 0.3673 & 1.8000 & 3.3000 & 206 \\
\hline & 0.4274 & 0.495 & 0.0000 & 1.0000 & 840 \\
\hline
\end{tabular}


From table 2, the mean export for the country pairs is US\$ 23.5 million with a standard deviation of US\$ 70.6 million. This statistics confirms the relative low intra trade flows among the EAC member states. The mean GDP for the exporting and importing trading partners is US\$ 5.6 billion with a standard deviation of US\$ 5.4 billion. This depicts the fact that the exports of one member state are the imports of the other trading partner.

The mean per capita for the exporting and importing member states are US\$ 341.4 and US\$ 324.2 with standard deviations of US\$ 257.6 and US\$239.3 respectively. The relative small size of the EAC member states economies as measured by their GDPs and the relative small per capita's could be used to explain the relative low intra trade flows among themselves compared to other regions like the ASEAN and EU trading blocks.

The mean FDI for both exporting and importing member states is US\$ 7.46 billion with a standard deviation of US\$ 1.66 billion. The mean population for both exporting and importing member states is about 16.4 million with a standard deviation of 10.5 million, a minimum of 3.5 million and a maximum of 43.1 million people. Of this population, the mean for those with mobile subscriptions is a paltry 0.8 million people, with a standard deviation of 0.28 million subscribers. The mean for diaspora remmitances is US\$ 4.9 million with a standard deviation of US\$ 1.5 million.

In summary, this sub-section describes the data used for analysis in this study, confirms some of the trade facts presented in the background and literature sections and offers some intuition into the expected results.

\section{Estimation Results and Discussions}

\subsection{Preliminary Simple OLS Estimations Results}

First, the study estimates a simple OLS regression for the variables selected to provide a snap shot view of the expected findings from randomised gravity model. The simple OLS equation is modelled along equation (4) for the selected variables as presented in equation 18:

$$
\begin{gathered}
E_{i j t}=\propto_{0}+\theta_{t}+\beta_{1} G D P_{i t}+ \\
\beta_{2} G D P_{j t}+\beta_{3} F D I_{i t}+\beta_{4} F D I_{j t}+\beta_{5} P_{i t}+\beta_{6} P_{j t}+\beta_{7} R c_{i t}+\beta_{8} R c_{j t}+\beta_{9} M p_{i t}+ \\
\beta_{10} M p_{j t}+\beta_{11} W_{i j t}+\beta_{12} S c_{t}+\beta_{13} B s_{t}+\mu_{i j t}
\end{gathered}
$$

Table 3. Preliminary simple OLS regression results

\begin{tabular}{lccc}
\hline & \multicolumn{2}{c}{ Baseline Results } & Std. err \\
\hline Variable & $\boldsymbol{\beta}$ 's & t-stats & 2.2737 \\
\hline $\mathrm{GDP}_{\mathrm{i}}$ & $19.9390^{* * * *}$ & $(8.77)$ & 2.0627 \\
$\mathrm{GDP}_{\mathrm{j}}$ & $8.1120^{* * *}$ & $(3.93)$ & 11.4375 \\
$\mathrm{Sc}$ & $19.5663^{*}$ & $(1.71)$ & 17.3811 \\
$\mathrm{Bs}$ & $141.1508^{* * *}$ & $(8.12)$ & 1.8600 \\
$\mathrm{FDI}_{\mathrm{i}}$ & $-1.2700^{* * *}$ & $(-6.80)$ & 1.7000 \\
$\mathrm{FDI}_{\mathrm{j}}$ & $-5.2000^{* * *}$ & $(-2.92)$ & 1.4627 \\
$\mathrm{P}_{\mathrm{i}}$ & $-5.7009^{* * *}$ & $(-3.90)$ & 1.3085 \\
$\mathrm{P}_{\mathrm{j}}$ & -1.9285 & $(-1.48)$ & 17.4451 \\
$\mathrm{Rc}_{\mathrm{i}}$ & $-29.4052^{*}$ & $(-1.89)$ & 18.1586 \\
$\mathrm{Rc}_{\mathrm{j}}$ & -4.6971 & $(-0.26)$ & 2.3400 \\
$\mathrm{Mp}_{\mathrm{i}}$ & $-7.7700^{* * *}$ & $(-3.32)$ & 2.3000 \\
$\mathrm{Mp}_{\mathrm{j}}$ & -3.1100 & $(-1.35)$ & 0.0191 \\
$\mathrm{~W}_{\mathrm{ij}}$ & $0.0583^{* * *}$ & $(3.05)$ & 20.7231 \\
$\mathrm{Constant}$ & $-107.5261^{* * *}$ & $(-5.19)$ & \\
$\mathrm{R}^{2}$ & 0.697 & & \\
$\mathrm{Adj} . \mathrm{R}^{2}$ & 0.6809 & & \\
\hline
\end{tabular}

Note. *** means significant at $1 \%$; ** means significant at $5 \%$; means significant at $10 \%$ confidence levels.

These estimates assume the existence of "frictionless" trade as propounded implicitly by the Heckscher-Ohlin trade model (Deardorff, 1995) and no impediments to trade outside the feasible range of OLS estimation. The geographical or spatial trade issues are captured via the border sharing dummy. Unlike in standard Gravity models where distance, location and size are explicitly specified, location in this approach is captured by a dummy variable equal to one, for countries sharing a border and zero for those that don't. Hence, it's simplistically and inherently assumed that this border sharing dummy captures all factors that influence transport costs, infrastructure and business services (Graner \& Isaksson, 2002). 
From table 3, unlike the Niringiye et al. (2010) study, the location variable coefficient is significant at 1 per cent levels of significance implying that contiguity as a proxy variable for distance, infrastructure and physical amenities plays a significant role in determining exports in the EAC region. This is consistent with earlier findings by Ackello-Ogutu and Echessa (1996) and (1998). Past colonial ties that proxy history is determined to weakly drive trade in the region at 10 per cent confidence level. Country size measured by a country's GDP levels are found to drive or significantly impact bilateral trade in the EAC region for both the exporting and importing country. This holds at $1 \%$ confidence levels and is consistent with the standard gravity model predictions.

Further results suggest that bilateral trade in EAC is negatively but significantly driven by FDI inflows into the exporting country. Whereas this finding seems to deviate from the norm, it can be explained away by the observation that most FDI inflows in the EAC region are into non regional exporting sectors of ICT, infrastructure and mining. Such investments have a sizeable time lag before they can positively impact bilateral trade. Moreover, where there is no time lag, most of the commodities extracted (oil and minerals) are exported outside the EAC region implying that the higher the FDI inflows the higher the trade diversion away from the EAC Regional Integration Schedule (RIS).

The net effect of population in the EAC region is negative but highly significant on the regional exports and also negative but statistically insignificant on the regional bilateral imports. Membership into a regional trading block has a negative and weak significant effect on trade flows for the exporting member state but a negative and insignificant impact for the importing country. This is in contrast to expectation under standard gravity models where countries entering into regional integration arrangements are expected to trade more. It is also in contrast with Eita and Ashipala (2008) findings for Namimbia. However, this may be explained by their multiple memberships into the various trading blocks and the existence of rampant practice of NTBs among member states that effectively hinder intra trade flows among them.

Finally, diaspora remittances appear to foster growth of both regional exports and imports in the EAC region. Notably, workers' remittances in the region are dominated by East Africans working in neighbouring countries and especially originating from Kenya's vibrant private sector pool of employees.

In conclusion and as noted earlier, these estimates are likely to be biased and thus the explicit random effects panel data model is applied to esteimate more robust results.

\subsection{Random Effects Panel Data Estimation Results}

A review of econometric literature suggests that the fixed effect model would seem to be more appropriate for our EAC analysis. However, the main problem with a fixed effects model in our case is that variables that do not change over time i.e. time invariant variables, cannot be estimated directly because the inherent transformation wipes out such variables. It is for this reason that a random effects model is preferred.

The estimation equation used for the Random Effects model is that proposed by Hausman and Taylor (1981) as defined by Serlanga and Shin (2007) and presented in equation (16). Applying the factors selected to estimate EAC trade flows, equation estimated is presented in 19.

$$
\begin{gathered}
E_{i t}=\alpha_{i}+\beta_{1} G D P_{i t}+\beta_{2} G D P_{j t}+\beta_{3} F D I_{i t}+\beta_{4} F D I_{j t}+\beta_{5} P_{i t}+\beta_{6} W_{i t}+\beta_{7} C I_{i t}+\beta_{8} C I_{j t}+\beta_{9} M p_{i t}+ \\
\beta_{10} M p_{j t}+\beta_{13} C l_{t}+\beta_{11} S c_{t}+\beta_{12} B s_{t}+\mu_{i t}
\end{gathered}
$$

Table 4. Random effects panel data model results

\begin{tabular}{lccc}
\hline \multicolumn{4}{c}{ Random Effects Model Results } \\
\hline Variable & $\boldsymbol{\beta}$ 's & t-stats & Std. err \\
\hline $\mathrm{GDP}_{\mathrm{i}}$ & $10.2985^{* * *}$ & $(4.28)$ & 2.4041 \\
$\mathrm{GDP}_{\mathrm{j}}$ & $7.1277^{* * *}$ & $(4.63)$ & 1.5403 \\
$\mathrm{Sc}$ & 30.1856 & $(0.92)$ & 32.9244 \\
$\mathrm{Bs}$ & $126.8497^{* * *}$ & $(2.92)$ & 43.382 \\
$\mathrm{Cl}$ & 87.3362 & $(1.64)$ & 53.1981 \\
$\mathrm{FDI}_{\mathrm{i}}$ & $-6.0200^{* * *}$ & $(-3.66)$ & 1.6500 \\
$\mathrm{FDI}_{\mathrm{j}}$ & $-2.7500^{*}$ & $(-1.93)$ & 1.4300 \\
$\mathrm{P}_{\mathrm{i}}$ & $-5.7122^{* * *}$ & $(-2.59)$ & 2.2034 \\
$\mathrm{~W}_{\mathrm{i}}$ & $0.0921^{* * *}$ & $(3.01)$ & 0.0306 \\
$\mathrm{CI}_{\mathrm{i}}$ & 2.5203 & $(0.37)$ & 6.7630 \\
\hline
\end{tabular}




\begin{tabular}{lccc}
\hline $\mathrm{CI}_{\mathrm{j}}$ & $15.1876 * *$ & $(2.09)$ & 7.2772 \\
$\mathrm{Mp}_{\mathrm{i}}$ & -5.4600 & $(-0.26)$ & 2.0700 \\
$\mathrm{Mp}$ & $-4.9800 * * *$ & $(-2.86)$ & 1.7500 \\
Constant & $-187.7988 * * *$ & $(-3.7)$ & 50.7700 \\
$\mathrm{R}^{2}$-within & 0.6323 & & \\
$\mathrm{R}^{2}$-between & 0.6718 & \\
$\mathrm{R}^{2}$-overall & 0.6773 & \\
Note. *** means significant at 1\%; * means significant at 5\%; * means significant at 10\% confidence levels.
\end{tabular}

The results presented in table 4 reflect a more robust analysis of the EAC bilateral Trade flows. The congruency of these results with results obtained elsewhere is striking. For instance, country size- proxied by the GDP of both exporting and importing country pairs is found to impact trade significantly at the 1 percent levels of significance. This is similar to findings of the simple OLS model where both the GDP of the exporting and importing member states are found to positively drive trade.

These findings are not only broadly in agreement with economic theory but are also consistent with other research findings in the region. Eita and Ashipala (2008) and Simwaka (2006) find similar results for Namibia and Malawi. In both studies, the coefficients for the two variables are positive and statistically significant. Border sharing is positive and significant at 1 per cent levels just as in the Namibian study. The Malawian study however finds contiguity to be insignificant but this defies both theoretical and empirical expectations.

For the first time in the EAC region, the impact of corruption on bilateral trade flows is investigated. The results suggest that corruption has a positive but insignificant impact on exports within EAC region and a positive and significant impact at the 5 per cent level on imports. This implies that corruption may be driving imports for some of the EAC countries from their partners while at the same time driving the capacity to produce for exports. In some sense, corruption appears to act as an "incentive" for exports and imports. This would not be absolutely unexpected considering the findings of Ackello-Ogutu and Echessa (1996) and (1998). Intuitively, unrecorded trade flows across borders would be driven by corruption either to by-pass country specific NTB or evade customs and other duties on cross border trade.

Impact of diaspora remittances on exports is found to be positive and significant at the 1 percent confidence levels, while FDI inflows are found to impact exports negatively within the EAC region. These results are similar to those obtained in the simpler model. The model also determines that common language is highly correlated to one or more of the other regressors hence rejected.

Further findings suggest that sharing a colony and having a coast line have a positive but statistically insignificant impact of trade flows within the region. Mobile subscriptions have a negative effect on trade flows with the effect being statistically significant for imports. This probably suggests the high cost of calling within the region and low mobile penetration especially in the hinterlands limits the levels of trade within the EAC. Intuitively, this findings do not come as a surprise given that most production in the EAC region is agricultural based and often done at the subsistence level. Poor mobile connectivity and high cost of calling within the region would thus limit access to markets across borders.

Overall, the results of the random effects model remain consistent with the simple OLS estimates except for the same colony that now become statistically insignificant and for mobile subscriptions that reverse from negatively significant for exports to negative significant for imports and vice versa. The model explains up to 63.3, 67.2 and 67.7 within, between and overall variabilities respectively of the trade flows within the region.

\section{Conclusion}

The study empirically examnied various variables that affect international trade flows and tests their relevance and practical applicability among EAC member states. It concludes that country size, contiguity, diaspora remittances and corruption factors positively drive trade within the EAC region while FDI flows, net population effects and communication costs (proxied by mobile subscriptions) hinder trade flows among member states. However, intra trade flows within the region remain small in comparative terms to other trading blocks of the world.

These findngs and the conclusions thereof adduce important insights into the determinants of bilateral trade in the EAC region with practical policy propositions. First, the member states need to prioritize strategic infrastructural investments in the region to reduce distance between them and boost trade flows among themselves. Second, it's plausible for member states to re-oriented FDI flows into the region from extraction of 
mineral resources towards expansion of industries and value addition into their agricultural outputs to enhance gains to trade. Third, diaspora remittances could be harnessed to expand the regions productive capacity and enhances gains to trade in the region. Finally, as envisioned in the EAC protocol, the member states must address the Non Trade Barriers that still exist in the individual member states to fully exploit benefits of integration.

It is thus incumbent on the member states to consistently seek to address the obstacle that impede trade among themselves to enhance their gains from international trade. Despite the insightful findings emanating from this study, it cannot be said to be exhaustive and thus there is need to explore the subject further in future studies.

\section{Acknowledgements}

This article is part of my thesis submitted for the award of a PhD (Economics) degree at the University of Dar es Salaam, Republic of Tanzania. I wish to take this opportunity to register my sincere appreciation to my academic supervisors Dr. Kenneth P. Mdadila and Prof. Longinus K. Rutasitara for your support and contributions during the course complete my thesis. Special thanks also go out to the various panellists during the proposal defense and the Viva Voce in which the thesis was presented during the development and examination process. Your valued contributions, critique, comments and inputs have contributed a lot in shaping the final version of this article.

\section{References}

Ackello-Ogutu, C., \& Echessa, P. N. (1996). Informal Cross-Border Trade between Kenya and Uganda. SD Publication series, Technical paper. Journal of British Ceramic Transitions, 99(5), 206-211.

Ackello-Ogutu, C., \& Echessa, P. N. (1998). Unrecorded Cross-Border Trade between Tanzania and her Neighbours: Implications for Food Security. SD Publication series, Technical paper No. 89, September 1998.

African Development Bank (AfDB) \& African Development Fund (ADF). (2010). Eastern Africa Regional Integration Strategy Paper (RISP), 2011-2015. Regional Departments - East (orea/oreb). October 2010.

Ahn, S. C., Lee, Y. H., \& Schmidt, P. (2001). GMM estimation of linear panel data models with time-varying individual effects. Journal of Econometrics, 101, 219-255. https://doi.org/10.1016/S0304-4076(00)00083-X

Amjadi, A., \& Yeats, A. (1995). Have Transport Costs Contributed to Relative Decline of Sub-Saharan African Exports? Some Preliminary Empirical Evidence. Policy Research Working Paper 1559. Washington DC: World Bank.

Ammon, M., Mjema, G. D., \& Kilindo, A. (2002). The Nyerere Legacy and Economic Policy Making in Tanzania. Dar es Salaam, Dar es Salaam University Press.

Anderson, J. E., \& Van-Wincoop, E. (2000). Gravity with Gravitas: A Solution to the Border Puzzle. Boston College Working Papers in Economics 485. Boston College Department of Economics.

Anderson, P. S. (1979). A Theoretical Foundation for the Gravity Equation. American Economic Review, 12(3), 1311-1326.

Bai, J., \& Ng, S. (2002). Determine the number of factors in approximate factor models. Econometrica, 70, 191-221. https://doi.org/10.1111/1468-0262-00273

Bougheas, S., Demetriades, P. O., \& Morgenroth, E. L. W. (1999). Infrastructure, Transport Costs and Trade. Journal of International Economics, 47, 169-189. https://doi.org/10.1016/S0022-1996(98)00008-7

Brun, J., Carrere, C., Guillaumont, P., \& De Melo, J. (2002). Has Distance Died? Evidence from a Panel Gravity Model. Unpublished manuscript, University of d'Auvergne.

Cheng, I., \& Wall, H. J. (2002). Controlling Heterogeneity in Gravity Models of Trade. Working Paper 1999-010C, Federal Reserve Bank of St. Louis.

Coe, D., \& Hoffmaister, A. (1999). North - South, Trade; Is Africa Unusual. Journal of African Economies, 8(2), 228-256. https://doi.org/10.1093/jae.8.2.228

Coulibaly, S., \& Fontagne, L. (2005). South-South trade-Geography matter. Journal of African Economics, 15(2), 313-341. https://doi.org/10.1093/jae/eji030

De Grauwe, P., \& Skuldeny, F. (2000). Inflation and productivity differentials in EMU. Mimeo, Department of Economics, University of Leuven.

De Sousa, J., \& Disdier, A. (2002). Legal Framework as a Trade Barrier - Evidence from Transition Countries: Hungarian, Romanian and Slovene Examples. Discussion Paper Series 26300, Hamburg Institute of International Economics. 
Deardorff, A. V. (1995). Determinants of Bilateral Trade: Does Gravity work in a Neoclassical World? NBER, Working Paper, No.5377. Cambridge, M.A: National Bureau of Economic Research (NBER).

Deardorff, A. V. (2001). International provision of trade services, trade, and fragmentation. Policy Research Working Paper Series 2548, The World Bank. https://doi.org/10.1111/1467-9396.00276

Economic Development in Africa Report. (2009). Strengthening Regional Economic Integration for Africa's Development. United Nations Conference on Trade and Development. United Nations, Geneva. Retrieved from http://www.un.org/

Egger, P. (2001). On the Problem of Endogenous Unobserved Effects of the Gravity Models. WIFO Working paper No. 132, Australian Institute of Economic Research, 2001.

Egger, P., \& Pfaffermayr, M. (2002). The Proper Econometric Specification of the Gravity Equation: A Three-way Model with Bilateral Interaction. Working Paper, Austrian Institute of Economic Research. https://doi.org/10.1007/s001810200146

Eita, J. H., \& Ashipala, J. (2008). Estimating Namibia's Export Potential: A Gravity Model Approach. UNDP, Namibia.

Foroutan, F., \& Pritchett, L. (1993). Intra-Sub-Saharan African Trade: Is it Too Little? Journal of African Economies, 74-105. https://doi.org/10.1093/oxfordjournals.jae.a036775

Foster, V. (2008). Overhauling the engine of growth: infrastructure in Africa. Africa infrastructure country Diagnostic. AICD Executive Summary, The World Bank, Washington DC.

Gad, M. (2009). A Better Future For Africa: Recommendations From The Private Sector. Paper prepared for the African Commission. Copenhagen: Confederation of Danish Industry

Glink, R., \& Rose, A. K. (2002). Does a Currency Union Affect Trade? The Time Series Evidence. European Economic Review, 46, 1125-51. https://doi.org/10.1016/S0014-2921(01)00202-1

Graner, M., \& Isaksson, A. (2002), Export Performance, In A. Bigsten, \& P. Kimuyu (Eds.), Structure and Performance of Manufacturing in Kenya. London: Palgrave.

Hausman, J. A., \& Taylor, W. E. (1981). Panel data and unobservable individual effect. Econometrica, 49, 1377-1398. https://doi.org/10.2307/1911406

Krugman, P.R., \& Obstfeld, M. (2006). International Economics: Theory and Policy (7th ed.). Published by Pearson.

Limao, N., \& Venables, A. J. (2001). Infrastructure, Geography Disadvantage And Transport Costs. World Bank Economic Review, 15(3), 451-479. https://doi.org/10.1093/wber/15.3.451

Longo, R., \& Sekkat, K. (2001). Obstacles to Expanding Intra-African Trade. OECD Technical Paper, No. 169. Paris: OECD. https://doi.org/10.1787/042583120128

Longo, R., \& Sekkat, K. (2004). Economic Obstacles to Expanding Intra-African Trade. World Development, 32(8), 1309-1321. https://doi.org/10.1016/j.worlddev.2004.02.006

Martinez-Zaroso, I., \& Nowak-Lehmann, F. (2003). Augmented gravity model: An application to Mercosur-European Union trade flows. Journal of Applied Econometrics, 18, 291-316. https://doi.org/10.1080/15140326.2003.12040596

Matyas, L. (1997). Proper Econometric Specification of the Gravity Model. The World Economy, 20, 363-68. https://doi.org/10.1111/1467-9701.00074

McCallum, J. (1995). National Borders Matter: Canada -U.S. Regional Trade Patterns. The American Economic Review, 85(3), 615-623.

Ndulu, B. J. (2006). Infrastructure, Regional Integration and Growth in Sub-Saharan Africa: Dealing With the Disadvantages of Geography and Sovereign Fragmentation. Journal of African Economies, AERC Supplement, 2, 212-244. https://doi.org/10.1093/jae/ej1033

Niringiye, A., Lubanga, T., Okwi, P., \& Kaija, D. (2010). Determinants of Export Participation in East African Agricultural Manufacturing Firms. Current Research Journal of Economic Theory, 2(3), 112-118.

Njinkeu, D., Wilson, J., \& Fosso, B. P. (2008). Expanding Trade Within Africa: The Impact of Trade Facilitation. World Bank Policy Research Working Paper 4790. https://doi.org/10.1596/1813-9450-4790

Obstfeld, M., \& Rogoff, K. (2000). The Six Major Puzzles in International Macro-economics: Is there a 
Common Cause? Working Paper No. 7777, National Bureau of Economic Research (NBER).

Ochieng, W. R., \& Maxon, R. M. (1992). An Economic History of Kenya. East African Educational Publishers Ltd.

Okubo, T. (2006). Trade Bloc Formation in Interwar Japan -A Gravity Model Analysis. HEI Working Paper No. $03 / 2006$.

Pesaran, M. H. (2002). Estimation and inference in large heterogeneous panels with cross section dependence. University of Cambridge DAE Working Paper No. 0305. https://doi.org/10.1115/34161

Phillips, P. C. B., \& Sul, D. (2002). Dynamic panel estimation and homogeneity testing under cross section dependence. Cowles Foundation Discussion Paper No. 1362, Yale University. https://doi.org/10.1111/1368-423X.00108

Portugal-Perez, A., \& Wilson, J. (2008). Trade costs in Africa: Barriers and opportunities for reform. World Bank Policy Research Working Paper 4619. Washington DC: World Bank. https://doi.org/10.1596/1813-9450-4719

Rodrik, D. (1999). Making Openness Work. Overseas Development Institute, London.

Senhadji, A. S., \& Montenegro, C. E (1999). Time Series Analysis of Export Demand Equations: A Cross-Country Analysis. IMF Staff Papers, 46, 259-273.

Serlanga, L., \& Shin,Y. (2007). Gravity Model of the Intra -EU Trade: Application of the Hausman -Taylor Estimation in Heterogeneous Panels with Common Time- Specific Factors. Journal of Applied Econometrics, 22(2), 361-381. https://doi.org/10.1002/jae.944

Simwaka, K. (2006). Dynamics of Malawi's Trade Flows: A Gravity Model Approach. Munich Personal RePEc Archive (MPRA) 2006.

Subramanian, A., \& Tamirisa, N. (2001). Africa's Trade Revisited. IMF Working Paper, African and Policy Development and Review Departments, WP/01/33. March, 2001.

Villoria, N. (2008). Estimation of Missing Intra-African Trade. GTAP Research Memoranda 2915, Center for Global Trade Analysis, Department of Agricultural Economics, Purdue University.

\section{Copyrights}

Copyright for this article is retained by the author(s), with first publication rights granted to the journal.

This is an open-access article distributed under the terms and conditions of the Creative Commons Attribution license (http://creativecommons.org/licenses/by/4.0/). 